\title{
Gas Phase Pressure Effects on the Apparent Thermal Conductivity of JSC-1A Lunar Regolith Simulant
}

\author{
Zeng-Guang Yuan ${ }^{1}$ \\ National Center for Space Exploration Research, Cleveland, Ohio 44135 \\ and \\ Julie E. Kleinhenz ${ }^{2}$ \\ NASA Glenn Research Center, Cleveland, Ohio 44135
}

\begin{abstract}
Gas phase pressure effects on the apparent thermal conductivity of a JSC-1A/air mixture have been experimentally investigated under steady state thermal conditions from $10 \mathrm{kPa}$ to $100 \mathrm{kPa}$. The result showed that apparent thermal conductivity of the JSC-1A/air mixture decreased when pressure was lowered to $80 \mathrm{kPa}$. At $10 \mathrm{kPa}$, the conductivity decreased to $0.145 \mathrm{~W} / \mathrm{m} /{ }^{\circ} \mathrm{C}$, which is significantly lower than $0.196 \mathrm{~W} / \mathrm{m} /{ }^{\circ} \mathrm{C}$ at $100 \mathrm{kPa}$. This finding is consistent with the results of previous researchers. The reduction of the apparent thermal conductivity at low pressures is ascribed to the Knudsen effect. Since the characteristic length of the void space in bulk JSC-1A varies over a wide range, both the Knudsen regime and continuum regime can coexist in the pore space. The volume ratio of the two regimes varies with pressure. Thus, as gas pressure decreases, the gas volume controlled by Knudsen regime increases. Under Knudsen regime the resistance to the heat flow is higher than that in the continuum regime, resulting in the observed pressure dependency of the apparent thermal conductivity.
\end{abstract}

\section{Nomenclature}

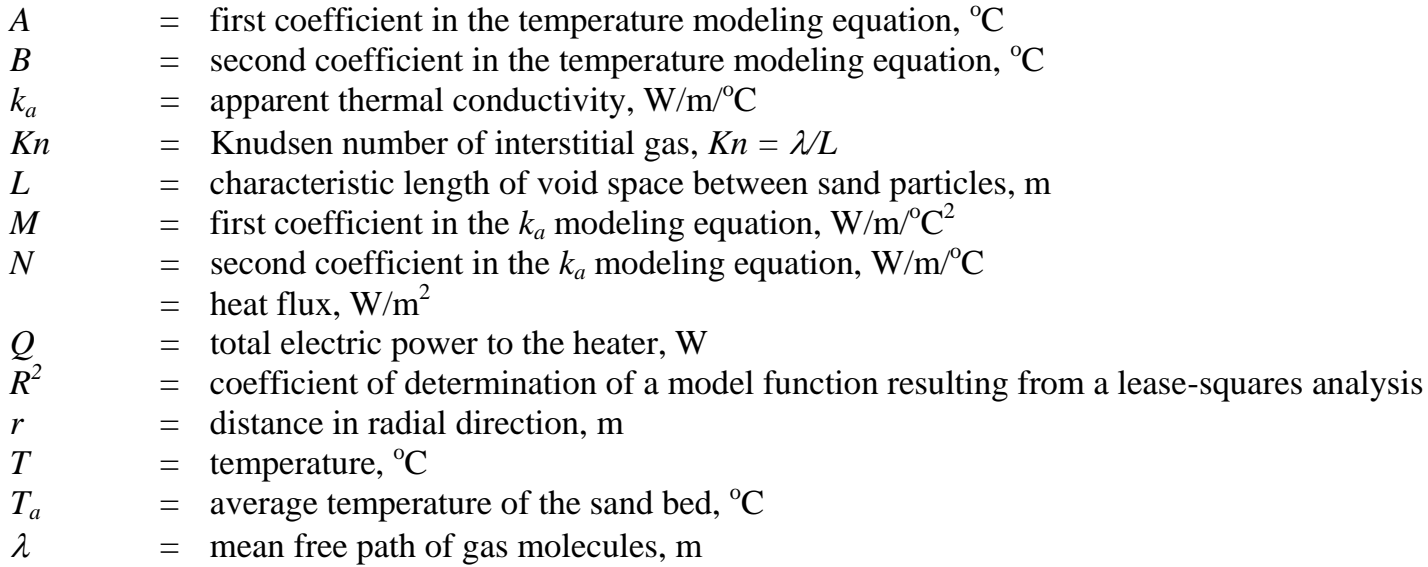

\section{Introduction}

$\mathrm{M}$ any current concepts for In Situ Resource Utilization (ISRU) on the Moon or Mars involve extraction of resources from the local ground material (regolith). Chemical reaction processes are used to target bound water and oxygen. These are typically endothermic reactions, such as hydrogen reduction, which require temperatures in excess of $1000^{\circ} \mathrm{C}$. Energy management and efficient system design are critical at these remote

\footnotetext{
${ }^{1}$ Staff Scientist, 21000 Brookpark Road, Cleveland, OH 44135, MS 110-3, AIAA Member.

2 Research Engineer, Propulsion and Propellants Branch, MS 301-3, 21000 Brookpark Road, Cleveland, OH 44135, Senior Member.
} 
locations and require knowledge of local material properties. JSC-1A lunar soil simulant is being used to develop these reactor systems, but its thermal properties have not been reported in the operating conditions of interest. The current research aims to explore these properties to enable accurate system design and analytical modeling efforts.

When dealing with granular materials, a local thermal equilibrium is often assumed if neither the temporal nor spatial temperature changes are rapid. Thus, the heat transfer problem can be formulated based on a control volume which is much larger than the size of individual solid particles and the representative pore size. Consequently, the granular material can be considered as a single phase composite material with a unified temperature field for the joined solid phase and fluid phase. The apparent thermal conductivity of the composite system is defined as follows.

where $k_{a}$ is the apparent thermal conductivity of the mixture of the simulant and the air, $T$ the bulk temperature of both solid phase and gas phase, and the combined heat flux from both solid and gas phases. Note that although Eq. (1) has the same form as Fourier's law, the two are fundamentally different. The thermal conductivity defined by Fourier's law is an intrinsic property of the material, whereas $k_{a}$, is not. In most applications the heat transfer in porous media is dominated by conduction; radiation is not important at low temperatures or low temperature gradients and convection is not important unless there is a strong forced convection. ${ }^{1-3}$

The objective of current work is to experimentally study the influence of gas phase pressure, below ambient pressures, on the apparent thermal conductivity of a JSC-1A/air system. Gas phase pressure effects on apparent thermal conductivity have been studied extensively in the past, both experimentally and theoretically. ${ }^{4-11}$ All experimental data show similar S-shaped curves when the apparent thermal conductivity is plotted against the gas phase pressure on a log-log scale. At zero gas pressure, i.e., under vacuum, the apparent thermal conductivity has a lowest value, then increases with pressure and finally approaches another constant.

The pressure dependency of the apparent thermal conductivity is attributed to the Knudsen effect, characterized by the Knudsen number $(K n)$, which is defined as the ratio of the mean free path of gas molecules, $\lambda$, to the characteristic length, $L$, between two solid walls that confine the gas: $K n=\lambda / L$. In the Knudsen regime, $K n \quad 1$, the gas phase can no longer be considered as a continuum. Temperature, in this case, is discontinuous between the gas and solid phases, and within the gas phase itself the Fourier law no longer holds. In a porous medium formed by loose particles, such as the JSC-1A/air system, the distances between the surfaces of two adjacent particles become diminishingly small before two surfaces contact each other. Therefore, under a given pressure, certain areas near those contact points will enter the Knudsen regime. As pressure decreases, the areas that change from continuum regime to Knudsen regime expand. This causes the apparent thermal conductivity to decrease with the gas phase pressure. The nature of this phenomenon is dependent on the geometry of the void space in the porous media, which is highly variable and difficult to model. Thus, it is difficult to predict exactly how the conductivity changes with pressure. Most existing models are based on simple, symmetric geometries, which have limited application to materials such as JSC-1A. However, the trend indicates that the Knudsen regime (and thus the thermal conductivity decrease) begins at higher pressures for smaller particle sizes. For practical application, information about pressure effects on the apparent thermal conductivity for a specific material can only be studied experimentally.

\section{Experimental Setup and Test Procedures}

The overall arrangement of the experimental setup is shown in Fig. 1. The test cell was designed and fabricated at NASA Glenn Research Center. The design of this apparatus permits temperature measurements in multiple locations within the sand bed, contrary to previous conductivity measurements which only measured temperatures at the boundary points of the tested material. ${ }^{12-15}$ This apparatus can also be operated at higher temperatures and at pressures lower than ambient. One of the primary design goals for the test apparatus was to establish a onedimensional, axisymmetric thermal field in the tested material. Previous investigations have shown that the apparent thermal conductivity of JSC-1A is very low, on the order of $0.2 \mathrm{~W} / \mathrm{m} /{ }^{\circ} \mathrm{C}^{12-15}$ A cylindrical geometry is more suitable for low conductivity measurements than a one-dimensional Cartesian arrangement because the latter relies on perfect insulation on the lateral surface, which is difficult to accomplish. The difficulty with the cylindrical geometry is the heat loss through both ends (bed surface and base), referred to as end effects. But, this can be mitigated by employing a large aspect ratio in the cylinder design.

The entire test cell is sealed for testing at sub-atmospheric pressures. A 57 liter buffer tank in the vacuum pump line stabilizes the pressure in the test cell. Other devices in Fig. 1 include two Tektronix PS280 DC power supply units with adjustable output voltage, the pressure transducer, the data logging boards and a laptop computer. The 
entire data logging system was calibrated and certified by the Calibration Laboratory at NASA John Glenn Research Center with NIST traceable standard devices.

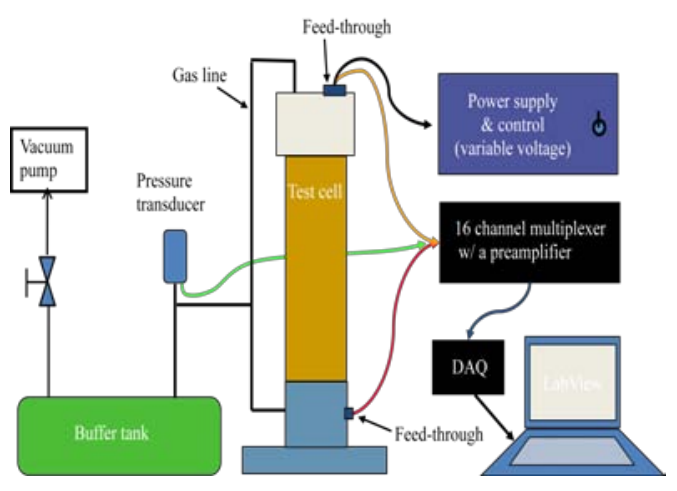

Figure 1. Experimental setup. The cylindrical test cell, is where JSC-1A regolith simulant is loaded and heated. Temperature data are recorded by a computer.

The JSC-1A sand under test is confined in the middle portion of the test cell by a quartz tube. The inner and outer diameters of the tube are $51.87 \mathrm{~mm}$ and $58.17 \mathrm{~mm}$, respectively, and its length is $300 \mathrm{~mm}$. Three supporting rods mounted on the base plus an upper plate form a frame accommodating ten Type K thermocouple (TC) wires and the electrical heater (Figure 2). The custom-built thermocouples are made of $0.2 \mathrm{~mm}$ diameter Chromel and Alumel wires, precision laser welded such that the TC junction has nearly the same diameter as the wires. The small junction size ensures more precise temperature readings. From each junction, the two wires run in opposite directions. All the negative wires (Nickel-Aluminum) go downward and positive wires (Nickel-Chromium) go upward. These wires are fixed at, and electrically insulated from, the top and bottom plates that support them. Figure 3 shows the locations of these thermocouple junctions. To facilitate verification of the one-dimensionality of the temperature field, the TC junctions were distributed in a 3D space. Five thermocouples, TC1, TC3, TC5, TC6 and the TC in the heater, are placed along the same radial line, whereas the other six TCs are placed either at different azimuthal or axial locations. Table 1, below, lists the coordinates of each TC junction.

Table 1. Coordinates of all TC junctions measured form high resolution photos

\begin{tabular}{|c|c|c|c|c|c|c|c|c|c|c|c|}
\hline & Htr. TC & TC6 & TC5 & TC4 & TC3 & TC2 & TC1 & TC8 & TC7 & TC9 & TC10 \\
\hline r, mm & $2.15^{* *}$ & 4.68 & 8.99 & 12.06 & 15.33 & 19.33 & 21.8 & 9.02 & 16.28 & 8.75 & 15.8 \\
\hline h, mm* $^{*}$ & $(63)^{* *}$ & 49.2 & 49.2 & 40.6 & 49.1 & 59.8 & 48.5 & 49.9 & 49.3 & 49 & 49.6 \\
\hline Azimuth, & 0 & 0 & 0 & 0 & 0 & 0 & 0 & 120 & 120 & 240 & 240 \\
\hline
\end{tabular}

*h is measured from the porous plate (see Fig. 3)

**The locations of the embedded TC in the heater are estimated.

A custom-designed Watlow cartridge heater, model WAT-EGA-12515, is located in the center of the test section. It has dimensions of $6.35 \mathrm{~mm}$ ID and $152.4 \mathrm{~mm}$ in length, rated at 400 watts with a $240 \mathrm{~V}$ input, and has an imbedded Type $\mathrm{K}$ thermocouple in the middle of the heated length. The heater sheath is made of Incoloy ${ }^{\circledR}$ which can be operated at $760^{\circ} \mathrm{C}$ max. According to the manufacturer, the heating wire is evenly coiled inside the heater. Thus, the heat generated per unit length should be uniform if the resistivity of the heating wire is constant. However, resistivity is a function of temperature and the temperatures are lower at the ends of the heater due to end-effects. The extent of this non-uniformity can be assessed based on the thermal coefficient of the resistivity of the heating wire. In this case, the wire is made of a nickel-chromium alloy with a thermal coefficient of resistivity to be $0.00015 /{ }^{\circ} \mathrm{C}$. Therefore, even if the temperatures at the two ends were lower by as much as $50^{\circ} \mathrm{C}$, the variation in the heat flux would still be negligible. This justifies the assumption of a uniform heat flux over the heated length of the heater. Once the total power to the heater is known, the heat flux can be obtained easily, which is important to the calculation of the apparent thermal conductivity. 
Figure 2. Photos of the test cell. The left photo shows the external view of the entire test cell and right photo shows the exposed thermocouple wires and the support frame.

\author{
Figure 3. A schematic of the test cell showing \\ the locations of thermocouples and the \\ supporting structure.
}

A total of 418 grams of JSC-1A lunar soil simulant was loaded into the test cell through the port on the upper plate (Fig. 2). During the filling process, the quartz tube was gently tapped to prevent cavities from forming in the sand bed. The height of the sand column in the test cell was $125 \mathrm{~mm}$, which gives a 5:1 ratio of height to radius of the sand bed. This large aspect ratio is important in minimizing the end effects so that a one-dimensional temperature distribution can be achieved. The bulk volume of the sand was estimated to be $248.18 \mathrm{~cm}^{3}$ by subtracting the volumes of the heater and the three supporting rods from the inner volume of the quartz tube. The corresponding bulk density of the sand is $1.684 \mathrm{~g} / \mathrm{cm}^{3}$.

\section{Results}

Results of 23 tests are reported in this paper. These tests were performed under 4 different nominal gas phase pressures: $100 \mathrm{kPa}, 75 \mathrm{kPa}, 25 \mathrm{kPa}$ and $10 \mathrm{kPa}$. The gas phase was the ambient, room air. Under each nominal gas pressure, five to six tests were performed with various heater powers, thus heat fluxes at heater surface. Heater temperature was maintained below $700{ }^{\circ} \mathrm{C}$, allowing a $60{ }^{\circ} \mathrm{C}$ safety margin of the heater. Each test lasted 4 to 5 hours to ensure the temperature distribution reached steady state. The steady state temperatures were determined by averaging the last 100 data points ( 6 minutes) of the test. Under the steady state, the standard deviation of the 100 data points of each run from each thermocouple was less than $0.25^{\circ} \mathrm{C}$.

Figure 4 presents temperature distributions of a group of six tests under the same nominal pressure, $100 \mathrm{kPa}$, but six different heater power levels. Similar plots were made for all pressure conditions. The symbols indicate the measured temperatures from all eleven thermocouples, including the one inside the heater. Note that two thermocouples were located at a radial distance of $9 \mathrm{~mm}$ so that they are not distinctly separate in Fig 4 . However, these two thermocouples are located at different azimuthal planes, suggesting that the temperature field is axisymmetric. More detailed verification of the one-dimensional temperature distribution in this apparatus can be found in Ref. 3. The one-dimensional temperature field assumption is important because it is the basis for the subsequent data reduction to obtain the apparent thermal conductivity.

The temperature distribution of each test can be modeled by a logarithmic function, as represented by the solid lines in Figure 4. This is true not only for the six tests shown in Fig. 4, but for all tests.

The heater power level, the gas phase pressure, the resulting regression coefficients ( $A$ and $B$ ), the coefficient of determination $\left(R^{2}\right)$, and two derived parameters: the apparent thermal conductivity and the average temperature, $T_{a}$, of all 23 tests are listed in Table 2. The coefficient of determination indicates how well Eq. (2) models the temperature distribution, with 1 being a perfect model. All $R^{2}$ values are very close to one, indicating that the data is well modeled. In Table 2, tests are divided into four groups designated by the first letter of the test ID. In group A, 
$\mathrm{B}$, C and D, the nominal gas phase pressures are $10 \mathrm{kPa}, 25 \mathrm{kPa}, 75 \mathrm{kPa}$ and $100 \mathrm{kPa}$, respectively. The corresponding actual average pressures and standard deviations are $9.997 \pm 0.124 \mathrm{kPa}$ for group A, $25.106 \pm 0.1056$ $\mathrm{kPa}$ for group B, $73.987 \pm 2.251 \mathrm{kPa}$ for group Cs and $99.914 \pm 0.699 \mathrm{kPa}$ for group D.

Table 2. The coefficients in Eq. (2), derived apparent thermal conductivities, and average temperatures for all six tests. Calculations used all 11 thermocouples.

\begin{tabular}{|c|c|c|c|c|c|c|c|}
\hline Test ID & Gas pressure, $\mathrm{kPa}$ & Heater power, W & $\mathrm{A},{ }^{\circ} \mathrm{C}$ & $\mathrm{B},{ }^{\circ} \mathrm{C}$ & $\mathrm{R}^{2}$ & $\mathrm{k}_{\mathrm{a}}, \mathrm{W} / \mathrm{m} /{ }^{\circ} \mathrm{C}$ & $\mathrm{T}_{\mathrm{a}},{ }^{\circ} \mathrm{C}$ \\
\hline A-1 & 9.92 & 6.05 & -50.24 & 189.72 & 0.9979 & 0.1508 & 49.70 \\
\hline A-2 & 10.13 & 10.71 & -86.63 & 312.73 & 0.9969 & 0.1550 & 71.29 \\
\hline A-3 & 9.82 & 16.71 & -132.60 & 468.51 & 0.9972 & 0.1579 & 98.95 \\
\hline A-4 & 10.06 & 23.79 & -181.20 & 634.95 & 0.9979 & 0.1645 & 129.95 \\
\hline A-5 & 10.04 & 32.09 & -235.30 & 818.48 & 0.9982 & 0.1709 & 162.70 \\
\hline B-1 & 24.93 & 2.68 & -19.55 & 86.47 & 0.9987 & 0.1721 & 31.99 \\
\hline $\mathrm{B}-2$ & 24.96 & 10.69 & -72.92 & 270.19 & 0.9988 & 0.1836 & 66.96 \\
\hline B-3 & 25.14 & 16.52 & -107.00 & 389.13 & 0.9988 & 0.1935 & 90.92 \\
\hline B-4 & 25.10 & 23.76 & -144.10 & 519.67 & 0.9991 & 0.2066 & 118.06 \\
\hline B-5 & 25.20 & 31.93 & -183.80 & 660.12 & 0.9992 & 0.2177 & 147.87 \\
\hline B-6 & 25.12 & 42.07 & -229.80 & 823.40 & 0.9992 & 0.2294 & 182.95 \\
\hline C-1 & 74.81 & 10.79 & -62.86 & 240.93 & 0.9985 & 0.2151 & 65.74 \\
\hline C-2 & 74.75 & 16.75 & -93.32 & 347.70 & 0.9985 & 0.2250 & 87.62 \\
\hline C-3 & 69.56 & 24.05 & -126.90 & 468.31 & 0.9990 & 0.2375 & 114.64 \\
\hline C-4 & 75.11 & 32.37 & -161.80 & 590.40 & 0.9992 & 0.2507 & 139.46 \\
\hline C-5 & 75.05 & 41.76 & -198.50 & 722.13 & 0.9993 & 0.2636 & 168.91 \\
\hline C-6 & 75.47 & 53.62 & -240.60 & 877.99 & 0.9991 & 0.2793 & 207.44 \\
\hline D-1 & 99.93 & 10.93 & -62.78 & 237.62 & 0.9989 & 0.2183 & 62.65 \\
\hline D-2 & 98.80 & 16.55 & -91.39 & 339.28 & 0.9987 & 0.2270 & 84.58 \\
\hline D-3 & 99.60 & 26.00 & -132.90 & 487.78 & 0.9992 & 0.2451 & 117.39 \\
\hline D-4 & 99.92 & 32.28 & -158.00 & 578.24 & 0.9992 & 0.2560 & 137.89 \\
\hline D-5 & 100.84 & 41.65 & -192.60 & 704.32 & 0.9993 & 0.2710 & 167.54 \\
\hline D-6 & 100.40 & 53.67 & -233.70 & 855.42 & 0.9991 & 0.2878 & 204.10 \\
\hline
\end{tabular}




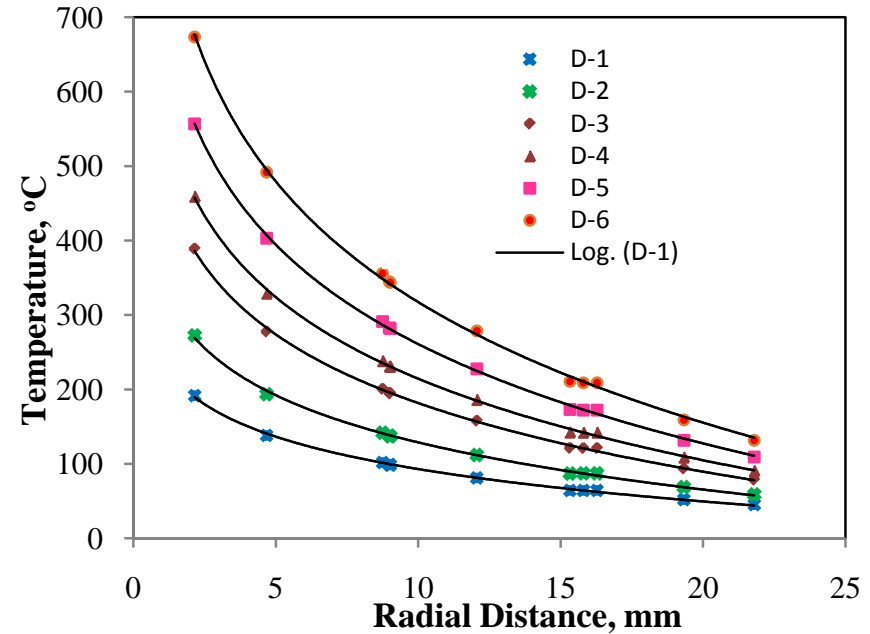

Figure 4. Temperature distribution of six tests in group D (100 kPa nominal) with least squares regression plots. For all the tests, the temperature distribution can be modeled by a logarithm function with high accuracy, indicating a constant $k_{a}$ for each test.

\section{Discussion}

For the 1-D axisymmetric test cell, the steady state temperature distribution can be described by the following equation.

where $Q$ is the total heat flow passing through the cylindrical surface with radius of $r$ and a length of $l$, which is the length of the heater in this case. Substituting Eq. (2) into Eq. (3) yields

At steady state, the total heat flow passing through all cylindrical surfaces concentric to the centerline of the test cell must be equal to the electric heater power. Thus, $Q$ in Eq. (4) is a constant independent of $r$. Based on the values of $Q$ and coefficient $A$ in Table 2, the corresponding apparent thermal conductivity of each test, $k_{a}$, can be calculated. This result is also listed in Table 2. Because the values of $Q$ and $A$ are unique for each test, the value of $k_{a}$ must be constant for each test at different radial locations. Since each test covers a wide temperature range from the heater to the inner wall of the quartz tube, the value of $k_{a}$ must be independent of temperature.

However, the values of $k_{a}$ in Table 2 appear to depend on both heater power and gas phase pressure. The pressure dependence is apparent between the four groups, but does not correlate to small pressure variations within the same group. The dependence on heater power is contradictory to the above conclusion that $k_{a}$ is independent of temperature. This phenomenon has been investigated in detail in a previous publication and was attributed to the effects of thermal stress. ${ }^{3}$ The average temperature of the soil increases with heater power, resulting in higher thermal stress within the test cell. The quartz tube expands very little because of very low thermal expansion coefficient and low temperature in the test. Thus, the thermal expansion in the soil is contained by a nearly rigid wall and results in larger contact area between adjacent particles and thus higher apparent thermal conductivity. It can be shown that the thermal stress in the test cell increases linearly with the volumetric average temperature in the test cell. For this particular test cell, the volumetric average temperature can be calculated based on the temperature profile of Eq. (2) and, the radii of the heater and the inner surface of the quartz tube. The results show that the average temperature is related to the regression coefficients A and B in Table 2, as shown in Eq. (5). More detailed derivation can be found in Ref. 3. The apparent thermal conductivity under stress-free condition can be obtained by evaluating $k_{a}-T_{a}$ correlation at $\mathrm{T}_{\mathrm{a}}=20^{\circ} \mathrm{C}$. The apparent thermal conductivities of different pressure groups are compared under the same stress-free condition.

The average temperature, $T_{a}$, of each test is also listed in Table 2. 


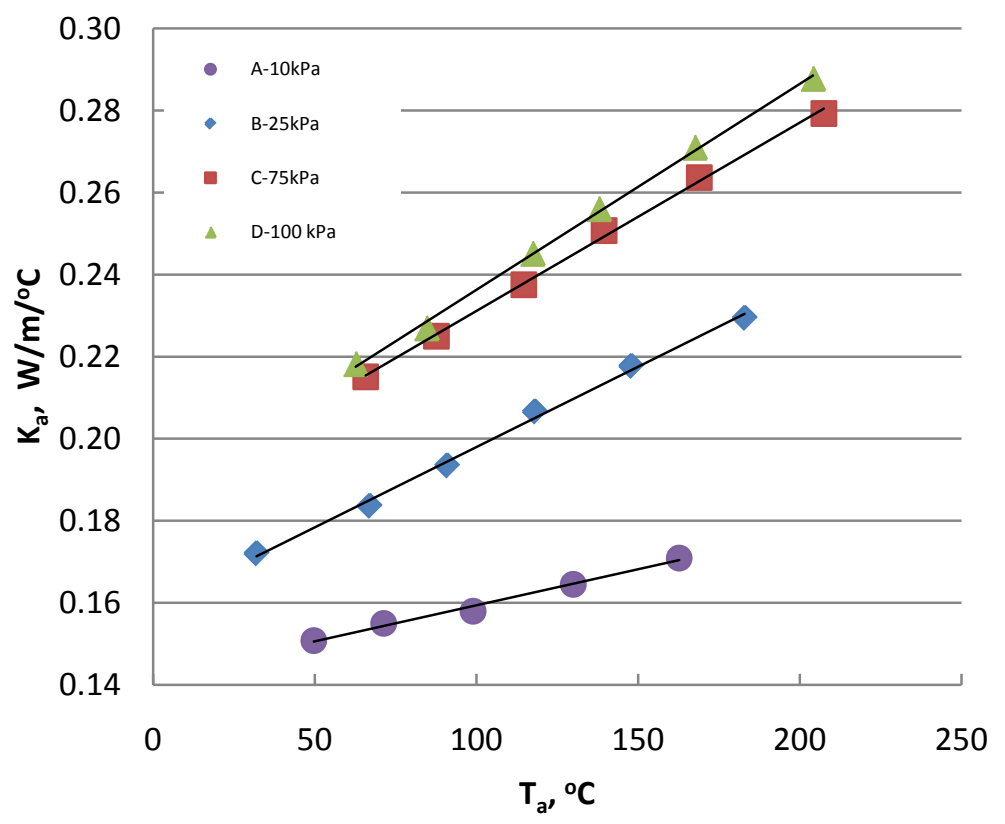

Figure 5. Correlation between the apparent thermal conductivity and average temperature of each pressure group of tests.
Figure 5 shows correlation between the apparent thermal conductivity and average temperature of tests in each pressure group. The symbols indicate the pressure group, whereas the solid lines are regression fits. Each line can be expressed with a linear equation between $k_{a}$ and $T_{a}$.

$$
k_{a}=M T_{a}+N
$$

where $M$ and $N$ are regression coefficients for each group. Table 3 lists the coefficients $M, N$, and $R^{2}$, as well as pressure data of the four groups of tests in this study. It can be seen that all the four coefficients of determination, $R^{2} s$, are very close to one, indicating Eq. 6 is indeed a good model for $k_{a} \sim T_{a}$ correlations. This model can be used to extrapolate the apparent thermal conductivity of the JSC-1A to a stress-free condition at $20^{\circ} \mathrm{C}$. To study gas phase pressure effect on the apparent thermal conductivity of JSC-1A, the conductivity values under stress free

condition should be used.

Table 3. Results of regression analysis of four test groups and the ka under stress-free conditions

\begin{tabular}{|c|c|c|c|c|c|c|c|}
\hline $\begin{array}{c}\text { Test } \\
\text { Group }\end{array}$ & $\begin{array}{c}\text { Nominal Pressure, } \\
k P a\end{array}$ & $\begin{array}{c}\text { Avg. Actual Absolute } \\
\text { Gas Pressure, } k P a\end{array}$ & Std. Dev., $k P a$ & $\begin{array}{c}\mathrm{M}, \\
W / m\end{array}{ }^{\circ} C^{2}$ & $\begin{array}{c}\mathrm{N}, \\
W / m /{ }^{\circ} \mathrm{C}\end{array}$ & $\mathrm{R}^{2}$ & $\begin{array}{c}\mathrm{k}_{\mathrm{a}} @ 20^{\circ} \mathrm{C}, \\
\mathrm{W} / \mathrm{m} /{ }^{\circ} \mathrm{C}\end{array}$ \\
\hline $\mathrm{A}$ & 10 & 10.00 & 0.124 & $1.755 \mathrm{E}-04$ & 0.1418 & 0.9909 & 0.1453 \\
\hline B & 25 & 25.11 & 0.106 & $3.914 \mathrm{E}-04$ & 0.1588 & 0.9966 & 0.1666 \\
\hline C & 75 & 73.99 & 2.251 & $4.593 \mathrm{E}-04$ & 0.1852 & 0.9984 & 0.1944 \\
\hline D & 100 & 99.91 & 0.698 & $5.021 \mathrm{E}-04$ & 0.1861 & 0.9986 & 0.1961 \\
\hline
\end{tabular}

Figure 6 shows the correlation between the apparent thermal conductivity $k_{a}$ at $20^{\circ} \mathrm{C}$, i.e., under stress-free condition and the average measured gas phase pressures. The symbols indicate experimental data, whereas the solid line is the least-squares regression with a second order polynomial function as follows.

$$
k_{a}\left(W / m /{ }^{\rho} C\right)=-8.66 E-6^{*} p^{2}+1.5 E-3 * p+0.133,
$$

where $p$ is the absolute pressure of the interstitial gas (air). The coefficient of determination of this fit is $R^{2}=0.995$. It can be seen that the apparent thermal conductivity of JSC-1A/air system is affected by the interstitial air pressure significantly in the pressure range between 10 to $100 \mathrm{kPa}$ (absolute). Note that the polynomial function presented here only applies to this pressure range. It should not be extrapolated on either side. When pressure is higher than $100 \mathrm{kPa}$, the apparent thermal conductivity is expected to approach a constant value. The behavior of the $\mathrm{k}_{\mathrm{a}}$ in the region of $p<10 \mathrm{kPa}$ is unknown. Because of the limitation of the hardware, we were unable to collect experimental data under the pressures in this region. However, for real applications such as ISRU on Moon, the value of regolith thermal conductivity at $0 \mathrm{kPa}$ is of interest. By extrapolating Eq. (6) to $0 \mathrm{kPa}$, we get $0.133 \mathrm{~W} / \mathrm{m} /{ }^{\circ} \mathrm{C}$. But considering the fact that the $k_{a} v$ s. $p$ curve has an S-shape ${ }^{9,11}$, the slope of the curve should decrease when approaching $0 \mathrm{kPa}$ from a higher pressure. Thus a number between 0.135 and $0.140 \mathrm{~W} / \mathrm{m} /{ }^{\rho} \mathrm{C}$ is recommended to use as the value of $k_{a}$ under vacuum condition. 


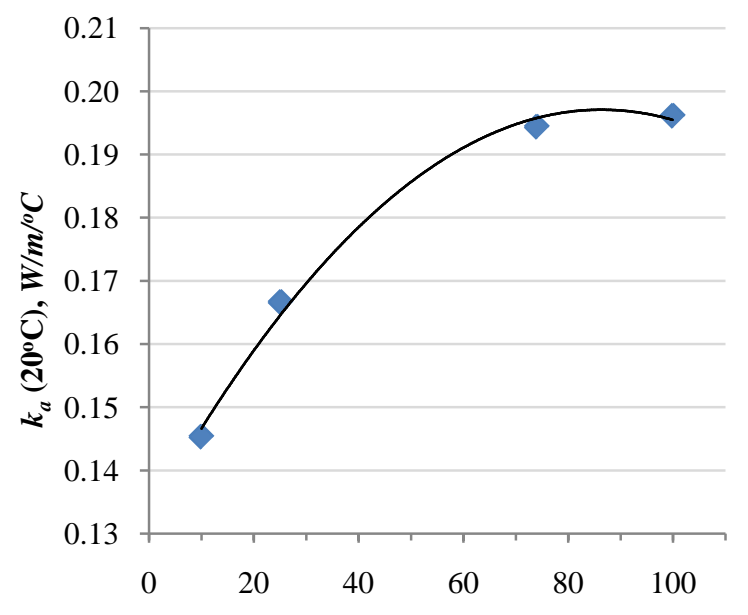

Absolute Gas Phase Pressure, $\mathrm{kPa}$

Figure 6. Apparent thermal conductivity of JSC-1A under stress free condition as a function of the absolute pressure of the interstitial gas, which is room air in this study. pressure is lower than $80 \mathrm{kPa}$, the apparent thermal conductivity decreases rapidly; from $0.196 \mathrm{~W} / \mathrm{m} /{ }^{\circ} \mathrm{C}$ at 99.9 $\mathrm{kPa}$ to $0.145 \mathrm{~W} / \mathrm{m} /{ }^{\circ} \mathrm{C}$ at $10 \mathrm{kPa}$. This is nearly a $25 \%$ reduction caused by $90 \mathrm{kPa}$ pressure drop. Within the pressure range of this investigation, the apparent thermal conductivity can be modeled by Eq. (7).

\section{Acknowledgments}

This work was supported by the In-Situ Resource Utilization Project. The majority of the apparatus was fabricated in 2009 under the Advanced Thermal Management Project. Both projects are part of the NASA ETDP/ETDD Program. The authors would also like to express their appreciation of the skilled efforts of Al Blaze and Donna Herbster in the fabrication and assembly of the apparatus.

\section{References}

\footnotetext{
${ }^{1}$ Yovanovich, M. M., and Marotta, E. E., “Thermal spreading and contact resistances,” in: Bejan, A. and Kraus, D. (Eds.), Heat Transfer Handbook, (Chapter 4), John Wiley \& Sons, New York, 2003.

${ }^{2}$ Arpaci, V. S. and Larsen, P. S., Convection Heat Transfer (Chapter 4), Prentice-Hall, Englewood Cliffs, NJ 07632, USA, 1984.

${ }^{3}$ Yuan, Z.-G., Kleinhenz, J. E., "Measurement of Apparent Thermal Conductivity of JSC-1A Under Ambient Pressure," AIAA-2011-009, 49th AIAA Aerospace Science Meeting, Orlando, Florida, U.S.A., January 4-7, 2011.

${ }^{4}$ Kling, G., "Das Warmeleitvermogen eines Kugelhaufwerks in ruhendem Gas,” VDI-Forschung, Vol. 9, 1938, pp. 28-34.

${ }^{5}$ Fulk, M. M., “Evaluation Powder Insulation for Low Temperatures,” Progress in Cryogenics, Vol. 1, $1^{\text {st }}$ ed., Heywood \& Company LTD., Great Britain, 1959, pp. 63-84.

${ }^{6}$ Masamune, S. and Smith J. M., "Thermal Conductivity of Beds of Spherical Particles," Industry and Engineering Chemistry Fundamentals, Vol. 2, 1963, pp. 136-143.

${ }^{7}$ Swift, D. L., "The Thermal Conductivity of Spherical Metal Powders Including the Effect of an Oxide Coating," International Journal of Heat and Mass Transfer, Vol. 9, 1966, pp. 1061-1074.

${ }^{8}$ Luikov, A. V., Shashkov A. G., Vasiliev L. L. and Fraiman Yu. E., “Thermal Conductivity of Porous Systems," International Journal of Heat and Mass Transfer, Vol. 11, 1968, pp. 117-140.

${ }^{9}$ Wakao, N. and Vortmeyer, D., "Pressure dependency of effective thermal conductivity of packed beds," Chemical Engineering Science, Vol. 26, 1971, pp. 1753-1765.

${ }^{10}$ Bahrami, M., Yovanovich, M. M., and Culham, J. R., "Effective thermal conductivity of rough spherical packed beds," International Journal of Heat and Mass Transfer, Vol. 49, 2006, pp. 3691-3701.

${ }^{11}$ Shapiro, M., Dudko, V., Royzen, V., Krichevets, Y., Lekhtmakher, S., Grozubinsky, V., Shapira, M., and Brill, M., "Characterization of Powder Beds by Thermal Conductivity: Effect of Gas Pressure on the Thermal Resistance of Particle Contact Points,” Part. Part. Syst. Charact. Vol. 21, 2004, pp. 268-275
} 
${ }^{12}$ Bernett, E. C., Wood, H. L., Jaffe, L. D., and Martens, H. E., “Thermal properties of a simulated lunar material in air and vacuum,” AIAA Journal, Vol. 1, No. 6, 1963, pp 1402-1407.

${ }^{13}$ Cremers, C. J., Birkebak, R. C., and Dawson, J. P., “Thermal conductivity of fines from Apollo 11," Proceedings of the APOLLO 11 Lunar Science Conference, Vol. 3, Houston, Texas, January 5-8, 1970, pp. 2045-2050.

${ }^{14}$ Cremers, C. J., and Birkebak, R. C., "Thermal conductivity of fines from Apollo 12," Proceedings of the Second Lunar Science Conference, Vol. 3, The M.I.T. Press, 1971, pp. 2311-2315.

${ }^{15}$ Horai, K., Simmons, G., Kanamori, H., and Wones, D., "Thermal diffusivity, conductivity and thermal inertia of Apollo 11 lunar material,” Proceedings of the APOLLO 11 Lunar Science Conference, Vol. 3, Houston, Texas, January 5-8, 1970, pp. 2243-2249. 